Article

\title{
Ion Transport in Solvent-Free, Crosslinked, Single-Ion Conducting Polymer Electrolytes for Post-Lithium Ion Batteries
}

\author{
Clay T. Elmore ${ }^{\dagger}$, Morgan E. Seidler ${ }^{\dagger}$, Hunter O. Ford, Laura C. Merrill, Sunil P. Upadhyay, \\ William F. Schneider ${ }^{(D)}$ and Jennifer L. Schaefer* ${ }^{(D)}$
}

Department of Chemical and Biomolecular Engineering, University of Notre Dame, Notre Dame, IN 46556, USA; Clay.T.Elmore.5@nd.edu (C.T.E.); Morgan.E.Seidler.10@nd.edu (M.E.S.); hford1@nd.edu (H.O.F.); Laura.C.Merrill.16@nd.edu (L.C.M.); Sunil.Upadhyay@va.gov (S.P.U.); wschneider@nd.edu (W.F.S.)

* Correspondence: Jennifer.L.Schaefer.43@nd.edu; Tel.: +1-574-631-5114

+ These authors contributed equally to this work.

Received: 14 May 2018; Accepted: 6 June 2018; Published: 7 June 2018

\begin{abstract}
Solvent-free, single-ion conducting electrolytes are sought after for use in electrochemical energy storage devices. Here, we investigate the ionic conductivity and how this property is influenced by segmental mobility and conducting ion number in crosslinked single-ion conducting polyether-based electrolytes with varying tethered anion and counter-cation types. Crosslinked electrolytes are prepared by the polymerization of poly(ethylene glycol) diacrylate (PEGDA), poly(ethylene glycol) methyl ether acrylate, and ionic monomers. The ionic conductivity of the electrolytes is measured and interpreted in the context of differential scanning calorimetry and Raman spectroscopy measurements. A lithiated crosslinked electrolyte prepared with PEG $_{31}$ DA and (4-styrenesulfonyl)(trifluoromethanesulfonyl)imide (STFSI) monomers is found to have a lithium ion conductivity of $3.2 \times 10^{-6}$ and $1.8 \times 10^{-5} \mathrm{~S} / \mathrm{cm}$ at 55 and $100^{\circ} \mathrm{C}$, respectively. The percentage of unpaired anions for this electrolyte was estimated at about $23 \%$ via Raman spectroscopy. Despite the large variances in metal cation-STFSI binding energies as predicted via density functional theory (DFT) and large variations in ionic conductivity, STFSI-based crosslinked electrolytes with the same charge density and varying cations $(\mathrm{Li}, \mathrm{Na}, \mathrm{K}, \mathrm{Mg}$, and $\mathrm{Ca}$ ) were estimated to all have unpaired anion populations in the range of 19 to $29 \%$.
\end{abstract}

Keywords: polymer electrolyte; single-ion conducting; ionic conductivity; Raman spectroscopy

\section{Introduction}

Advanced energy storage devices are desired to support next-generation consumer electronics and defense technologies, facilitate widespread electric vehicle adoption, and increase the penetration of renewably-generated electricity into the grid. Worldwide, research in battery materials and technology seeks to address these needs. Post-lithium ion batteries, including those based on lithium metal and other more abundant materials, are under active investigation. Next-generation battery electrolytes that allow for improved safety, maintained or longer device lifetimes, and that support post-lithium ion platforms are highly desired [1-6].

The most common Li-ion battery electrolytes that are used today are based on organic aprotic solvents, such as organic carbonates, and used in conjunction with a microporous polymer separator or imbibed in a polymer gel. These electrolytes exhibit high Li-ion conductivity and support an adequate solid-electrolyte-interface (SEI) formation, but they present many practical disadvantages, such as being volatile and flammable $[1,5,7,8]$. One class of electrolytes that are seen as a possible alternative are polymer electrolytes (PE). PEs offer many advantages, including improved thermal 
and electrochemical stability $[2,9,10]$. Inorganic solid electrolytes typically have even better thermal stability, but they do not offer the same flexibility as PEs, which may inhibit their use in large-format devices [5,11].

A specific class of PEs of recent increased research interest is the single-ion conducting polymer electrolyte (SIPE) [12]. The typical molecular structure of the SIPE for a lithium-ion battery is a lithiated ionomer with poly(ethylene oxide) (PEO) functionality and tethered anions [13-21]. SIPEs can have very high oxidative stabilities and support higher charge/discharge rates than polymer electrolytes of similar conductivities and non-unity transference numbers [16,22]. The free anion in a traditional polymer electrolyte with a mobile salt is usually the limiting factor for electrochemical stability with the lowest oxidative stability in the electrolyte. In the SIPE, the anion is fixed to the polymer backbone and does not migrate to the anode where it would otherwise degrade.

The ionic conductivity of SIPEs is heavily influenced by the chemical nature of their anion. Anions with delocalized electron densities have been shown to enable high ionic conductivities, because the delocalized charge promotes dissociation of the ion pair and increases free cation concentration in the solvating polymer (such as the PEO chain) [13,18,23-26]. One such highly delocalized tethered anion is (4-styrenesulfonyl)(trifluoromethanesulfonyl)imide (STFSI). An even more delocalized tethered anion, 4-styrenesulfonyl)(trifluoromethyl(S-trifluoromethylsulfonylimino)sulfonyl)imide] (SsTFSI), has been shown to enable record ionic conductivity of a dry SIPE $\left(1.35 \times 10^{-4} \mathrm{~S} / \mathrm{cm}\right)$, however, its synthesis is complex [13].

Furthermore, the macromolecular architecture also has a large impact on the performance of a SIPE. Longer amorphous chain segments allow fast segmental dynamics and, therefore, faster cation mobility; however, if the PEO segments are too long, the chains will crystallize resulting in drastically reduced cation mobility $[15,18]$. Electrolytes incorporating polymerized poly(ethylene glycol) methyl ether acrylate (PEGMA) have been shown to support high ionic conductivities over a wide temperature range. One such system is the random PEGMA-STFSI copolymer; unfortunately, these polymers are sticky gels and not convenient for battery fabrication [17]. Previous work has been done with poly(ethylene glycol) diacrylate (PEGDA) to create crosslinked, polymer electrolyte films. An important potential advantage to these crosslinked polymer electrolytes is their ability to be blade-coated directly on electrode sheets. However, PEGDA is available commercially at low cost only for short chain lengths $\left(M_{n} \sim 700 \mathrm{~g} / \mathrm{mol}\right)$, and crosslinked electrolytes based on this short PEGDA and without liquid plasticizer exhibit quite low ionic conductivities. Potential solutions to this challenge include the use of longer chain PEGDA and the copolymerization of PEGDA and PEGMA [27-31].

The most researched SIPE systems to date have been lithium-ion based SIPEs. Next-generation batteries based on other metals, such as $\mathrm{Na}, \mathrm{Mg}$, and $\mathrm{Al}$, however, are under increasing investigation due to the increased widespread abundance of these elements. Lithium reserves are located in sporadic locations around the globe [32-35]. In contrast, $\mathrm{Mg}, \mathrm{Na}$, and $\mathrm{K}$ can be harvested commercially from ocean water [32-34,36]. The commercial availability of $\mathrm{Mg}$, combined with its high energy capacity, makes $\mathrm{Mg}$ a great candidate for an alternative platform to Li for high energy density batteries [36-38]. Other metals, including $\mathrm{Na}$, have lower specific energy capacity, but are under active investigation for grid-level energy storage platforms [39-48].

Herein, we report on the ion transport properties of solvent-free, crosslinked SIPEs for post-lithium ion batteries. The use of longer chain PEGDA and the copolymerization of PEGDA and PEGMA are investigated in tandem with tethered anion chemistry and counter-cation type. The specific effects of segmental mobility and ion pairing on the conductivity are quantified via differential scanning calorimetry, Raman spectroscopy, and density functional theory (DFT) binding energy calculations.

\section{Results and Discussion}

Crosslinked electrolytes were prepared as described in the methods by the polymerization of PEGDA of varying molecular weights $\left(M_{n}=700,1000,1600,2150\right.$, and $\left.4700 \mathrm{~g} / \mathrm{mol}\right)$, PEGMA $\left(M_{n}=480 \mathrm{~g} / \mathrm{mol}\right.$ and $\left.750 \mathrm{~g} / \mathrm{mol}\right)$, and an ionic monomer, followed by ion-exchange and drying. 
The molecular structures of the electrolytes are shown in Figure 1. The ion content was held constant at a ratio of 1:30 moles charge:moles ethylene oxide (EO) for all cases described here. This ion content was chosen as we have found several poly(ethylene) glycol-based ionomers to have an optimum conductivity in an intermediate temperature range at this ion content. These include PEG ${ }_{31}$ DA-x-STFSILi and PEG ${ }_{31}$ DA-x-SSLi crosslinked ionomers as further studied here for temperatures of $40-90{ }^{\circ} \mathrm{C}$, as well as the bottlebrush copolymer PEG9MA-ran-STFSILi.

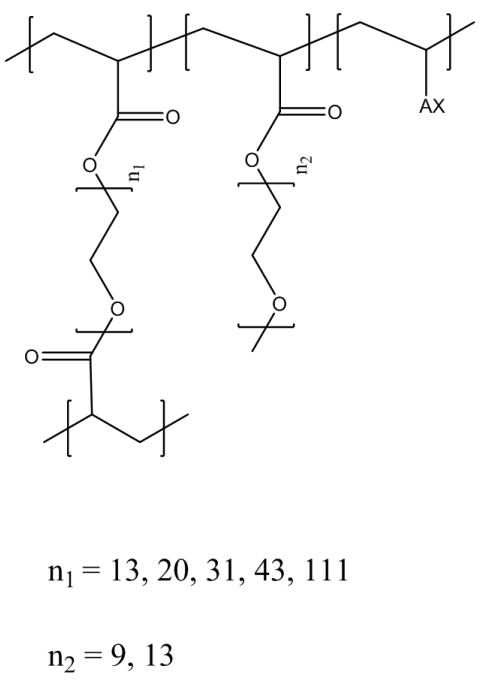

(a)
(1)

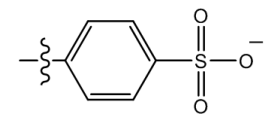

(2)<smiles>CC(=O)OCCCS(=O)(=O)[O-]</smiles>

(3)

(4)<smiles></smiles>

(5)<smiles>CC(=O)OCCCS(=O)(=O)[N-]S(=O)(=O)C(F)(F)F</smiles>

(b)

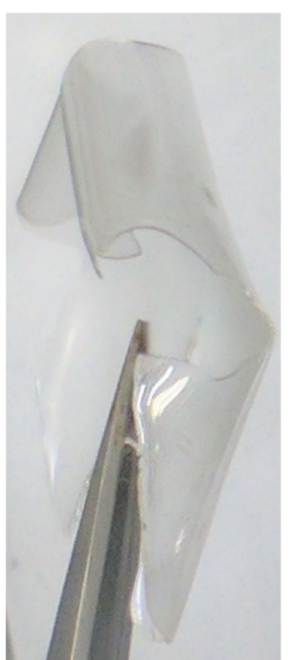

(c)

Figure 1. Chemical structures of (a) crosslinked ionomeric electrolytes, where $A$ is the tethered anion and $X$ is the counter-cation, and (b) the tethered anions, referred to as follows: (1) SS, (2) APS, (3) VS, (4) STFSI, and (5) APTFSI. A photograph of a typical crosslinked electrolyte is shown in (c).

Lithiated single-ion conducting electrolytes were prepared with five different common tethered anions: styrene sulfonate (SS), vinyl sulfonate (VS), acrylate-propylsulfonate (APS), (4-styrenesulfonyl)(trifluoromethanesulfonyl)imide (STFSI), and acrylate-propyl (trifluoromethanesulfonyl) imide (APTFSI). The TFSI-derivatives have been shown to be more dissociable, resulting in higher ionic conductivities than the sulfonates, but the chemical structure of the polymerizable group alters the rigidity of the ionomer which also affects ionic conductivity. This experiment was undertaken so that the relative effects of ion pair dissociation and segmental mobility on the ion transport could be compared over the temperature range of -20 to $100{ }^{\circ} \mathrm{C}$. Figure 2a displays the ionic conductivity of the electrolytes based on the varying bound anions, while Figure $2 \mathrm{~b}$ displays the measured glass transition temperatures $\left(T_{g} s\right)$ of the electrolytes and the DFT predicted dissociation energies of the bound anion-Li ion pairs. Lower $T_{g} \mathrm{~s}$ are correlated with higher chain segmental mobilities, and lower dissociation energies are correlated with higher mobile cation concentrations. Comparison of Figure 2a,b suggests that the degree of tethered anion dissociability most influenced the conductivity at high temperatures, whereas segmental mobility has an increased influence at low temperatures. Notice that at high temperatures, approaching $100^{\circ} \mathrm{C}$, the electrolytes containing TFSI-based anions exhibit ionic conductivities of over one order of magnitude greater than that of the sulfonate-based electrolytes; this difference is much diminished at low temperatures. This indicates that the ion pair dissociation and ion mobility have different activation energies [19]. This effect is also made apparent when comparing styrenic and non-styrenic monomers. The influence of higher glass transition temperatures and, therefore, reduced segmental mobility for the styrene-based ionic monomers results in a more appreciable decrease in conductivity $(\sigma)$ at lower temperatures. Specifically, $T_{g}$,APTFSI $<T_{g}$,STFSI and $T_{g}$,VS $<T_{g}$,APS $<T_{g, \text { SS }}$; at $-20{ }^{\circ} \mathrm{C}, \sigma_{\mathrm{APTFSI}}>\sigma_{\mathrm{STFSI}}$ and $\sigma_{\mathrm{VS}}>\sigma_{\mathrm{APS}}>\sigma_{\mathrm{SS}}$. This same trend does not hold at higher temperatures. 


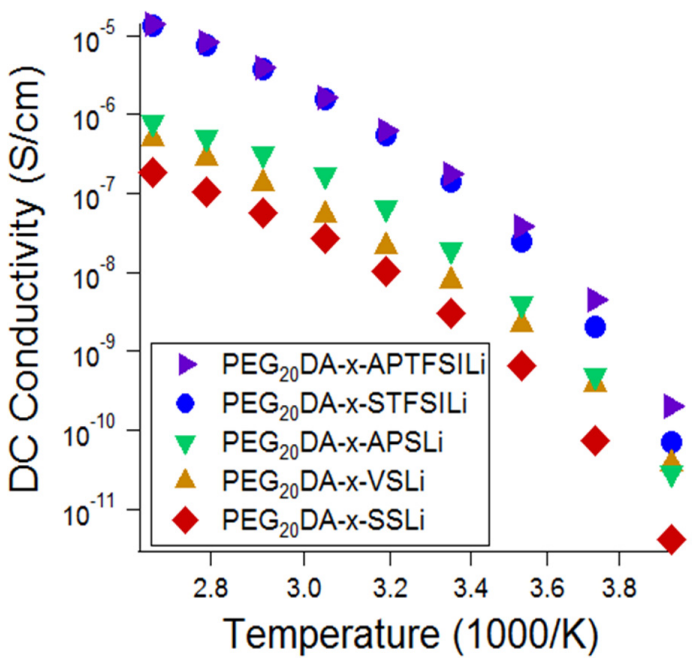

(a)

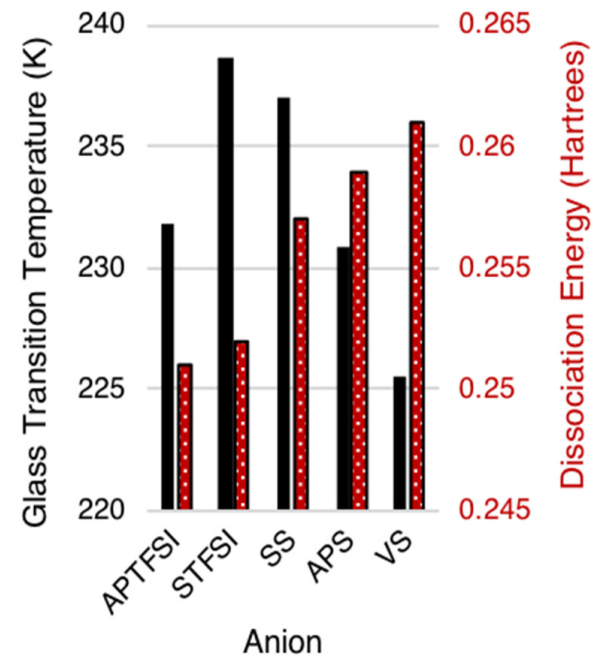

(b)

Figure 2. (a) DC conductivity from -20 to $100{ }^{\circ} \mathrm{C}$ for electrolytes containing the five different anions, and (b) corresponding experimental $T_{g}$ values for these electrolytes and DFT calculated dissociation energies for ion pairs $\mathrm{ALi}$, where $\mathrm{A}$ is the anion on the $\mathrm{y}$-axis.

Of the investigated tethered anion types, electrolytes containing APTFSI exhibited the highest ionic conductivity over the measured temperature range with SFTSI electrolytes exhibiting just slightly lower conductivities. The remaining investigations reported here employed electrolytes based on STFSI, as despite the slightly reduced conductivities, we found that this monomer was easier to prepare with high purity.

We also found that the differences in binding energies between the sulfonate and modified anions resulted in different mesoscale structures, as observed with small angle and wide angle X-ray scattering (SAXS-WAXS, Figure 3). Markedly less structure was observed in the intermediate angle region, corresponding to nanometer length scales, for the crosslinked ionomers containing STFSI than for those containing SS. The correlation at point $q_{\mathrm{a}}$, corresponding to a characteristic distance of about $5 \mathrm{~nm}$, is clearly present in PEG ${ }_{31} \mathrm{DA}-\mathrm{x}-\mathrm{SSLi}$, but absent for PEG ${ }_{31} \mathrm{DA}-\mathrm{x}-\mathrm{STFSILi}$, which instead displays a minor shoulder at point $q_{\mathrm{b}}$, a real-space distance of about $2.5 \mathrm{~nm}$. Likewise, $\mathrm{PEG}_{13} \mathrm{DA}-\mathrm{x}-\mathrm{SSLi}$ clearly displays a correlation length at point $q_{c}$, a characteristic distance of about $2 \mathrm{~nm}$, which is again much less prominent for PEG $_{13}$ DA-x-STFSILi. For these materials we hypothesize that evolution of a correlation length is indicative of the formation of ionic aggregates, a process which is partly governed by the degree of ion pair dissociation. With a low degree of dissociation, as is observed in the case of the SS anion, ionic charges are screened due to anion-cation pairing. This allows for the micro-phase separation of the polymers into PEGDA-rich and ionic unit-rich domains, a process which is subject solely to the physical constraints of the network crosslinking. However, as the dissociation degree increases, a greater number of unpaired anions exist in the crosslinked network. The tethered negative charges of the unpaired anions mitigate aggregation via electrostatic repulsion, resulting in a more uniform distribution of scatterers.

As the network crosslinker chain length increases, the ability of the polymer to accommodate greater aggregation increases, which results in the longer characteristic distances between ionic aggregates in the case of PEG $_{31} D A-x-S S L i$ relative to PEG $_{13} D A-x-S S L i$. In addition, longer crosslinkers facilitate aggregation in the case of the PEG ${ }_{31} \mathrm{DA}-\mathrm{x}-\mathrm{STFSILi}$, as the enhanced conformational freedom of the $\mathrm{PEG}_{31} \mathrm{DA}$ allows for the exclusion of unpaired anions while facilitating some degree of micro-phase separation of paired ionic groups. 


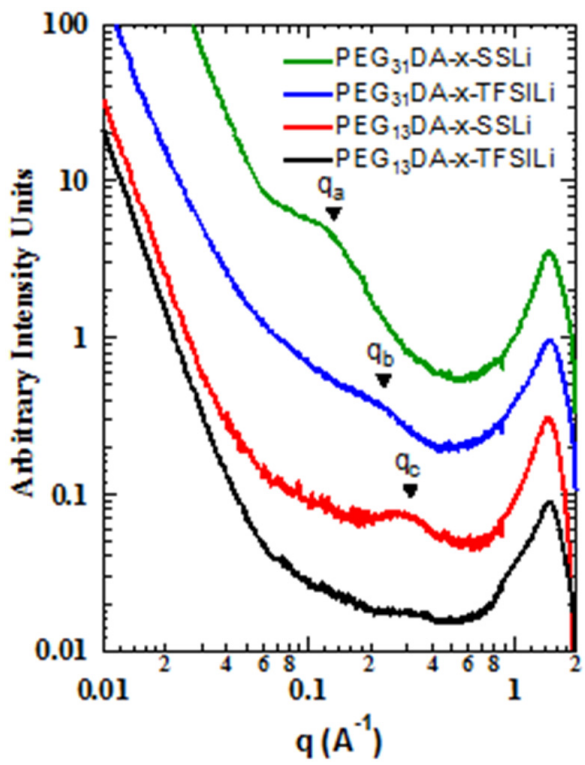

Figure 3. Small and wide angle X-ray scattering data on select crosslinked electrolytes at room temperature. Scattering vectors $(q)$ corresponding with ionic aggregation are noted.

The influence of the network morphology of the lithiated crosslinked ionomers, namely the crosslinker length and presence branching, on the ionic conductivity was also investigated (Figure 4). Glass transition and melting transition temperatures, as well as ionic conductivity at $55^{\circ} \mathrm{C}$, as a function of crosslinked ionomer composition, is summarized in Table A1 in Appendix A. Ionic conductivity was found to be a strong function of PEGDA crosslinker length at ambient temperature, with PEG $_{31} \mathrm{DA}$ resulting in the highest ionic conductivity at temperatures up to $40{ }^{\circ} \mathrm{C}$. For temperatures in the range of $55^{\circ} \mathrm{C}$ to $100{ }^{\circ} \mathrm{C}$, the conductivity of the electrolytes prepared with crosslinkers in the range of $\mathrm{PEG}_{20} \mathrm{DA}$ to $\mathrm{PEG}_{111} \mathrm{DA}$ was similar. These results are attributed to the competing effects of segmental mobility, ion pairing, and crystallization. Glass transition temperatures decreased and, therefore, segmental mobility increased, with increasing crosslinker length. Crosslinkers of $\mathrm{PEG}_{43} \mathrm{DA}$ and longer were found to create networks that crystallized, resulting in a drop off in ionic conductivity at temperatures below the amorphous-crystalline transition. Crosslinkers of $\mathrm{PEG}_{31} \mathrm{DA}$ and $\mathrm{PEG}_{20} \mathrm{DA}$, while semi-crystalline in the monomer form, produced crosslinked networks that remain amorphous at all temperatures. Finally, we suspect that there is an effect of tethered anion proximity that results in increased ion pairing for the long crosslinkers. On average, there are more adjacent tethered anions with increased crosslinker length for materials with the same overall ion content. Anions adjacent along the chain are more likely to have polarizability volume overlap, which results in a lower degree of cation dissociation and therefore a lower effective mobile ion number $[49,50]$. These combined effects explain the non-monotonic relationship of ionic conductivity and network crosslinker length at various temperatures.

The addition of PEGMA combs was found to only modestly improve the ionic conductivity of the electrolytes, if at all. Representative data is shown in Figure $4 \mathrm{~b}$, which shows the effect of varying the ratio of $\mathrm{PEG}_{9} \mathrm{MA}$ to $\mathrm{PEG}_{13} \mathrm{DA}$ in the range of $0: 1$ to $4: 1$, where ionic conductivity is improved only in limited cases. We also investigated the addition of $\mathrm{PEG}_{9} \mathrm{MA}$ combs to networks based on $\mathrm{PEG}_{20} \mathrm{DA}$, as well as the addition of $\mathrm{PEG}_{14} \mathrm{MA}$ to networks based on $\mathrm{PEG}_{31} \mathrm{DA}$, and found similar results. Thus, we conclude that greater enhancements in conductivity due to chain branching are likely only when the networks approaches a loosely crosslinked bottlebrush, wherein there are nearly all PEGMA combs and a limited number of PEGDA crosslinkers. With the network fabrication methods utilized here and described in the experiment, we were unable to realize a soft solid of this morphology. 


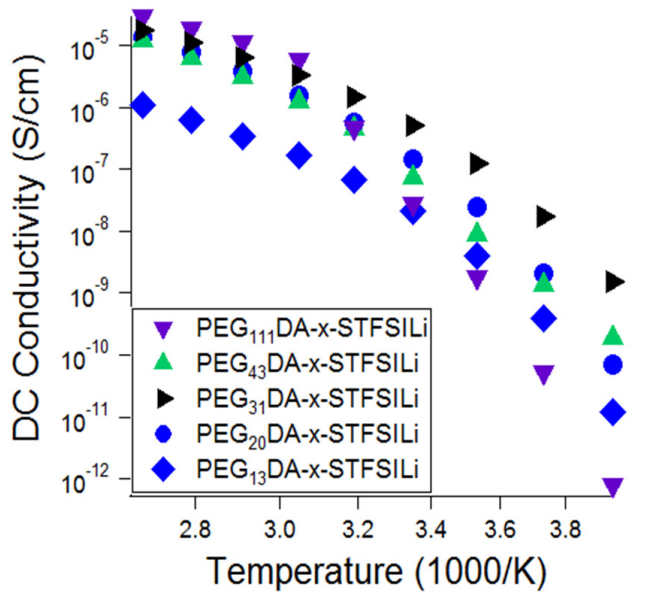

(a)

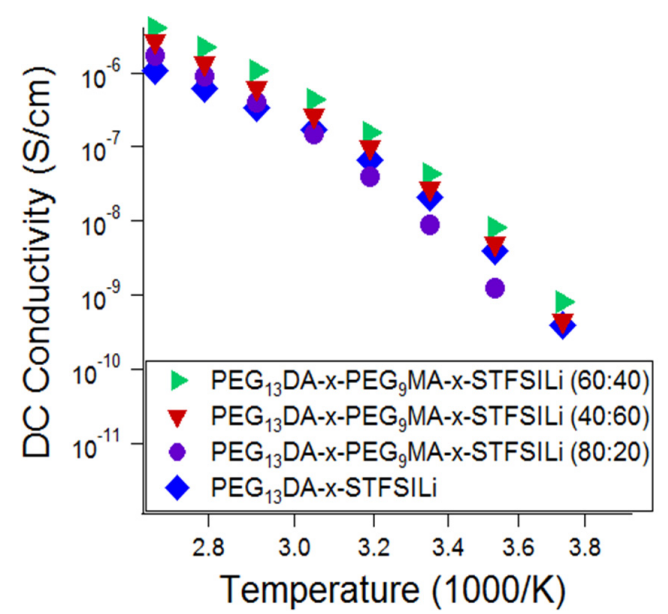

(b)

Figure 4. DC ionic conductivity from -20 to $100{ }^{\circ} \mathrm{C}$ for crosslinked electrolytes with (a) varying PEG crosslinker length and (b) varying ratios of crosslinker PEGDA and side-chain PEGMA.

The lithiated crosslinked electrolyte PEG $_{31}$ DA-x-PEG ${ }_{14} M A-x-S T F S I L i$ was employed in a symmetric lithium metal coin cell and galvanostatically cycled to confirm its ability to reversibly strip and plate lithium metal. This electrolyte does effectively cycle lithium metal, as shown in Figure 5, with a small, but observable, increase in resistance over $150 \mathrm{~h}$.

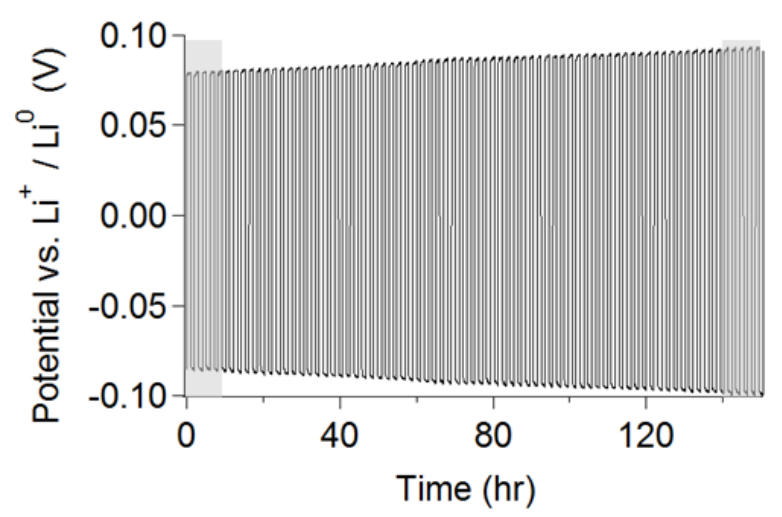

(a)

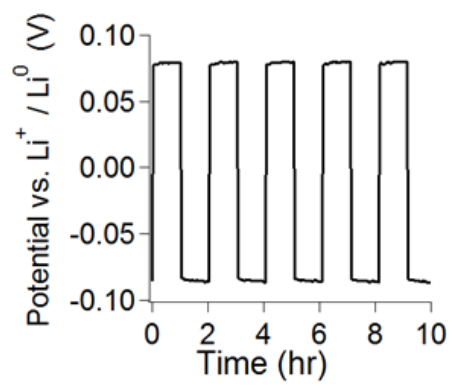

(b)

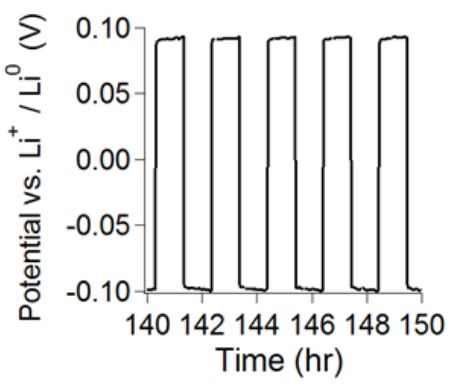

(c)

Figure 5. Galvanostatic cycling of a Li/PEG ${ }_{31} \mathrm{DA}-\mathrm{x}-\mathrm{PEG}_{14} \mathrm{MA}-\mathrm{x}-\mathrm{STFSILi} / \mathrm{Li}$ coin cell at $50 \mu \mathrm{A} / \mathrm{cm}^{2}$ at $70{ }^{\circ} \mathrm{C}$ : (a) time period of 0 to $150 \mathrm{~h}$, with shaded areas displayed on a larger scale in $(\mathbf{b}, \mathbf{c})$.

With an eye toward post-lithium ion battery chemistries based on more abundant elements, crosslinked electrolytes were exchanged to other metal cations using aqueous ion-exchange solutions 
of other metal chloride salts. The metal cation-STFSI binding energies were predicted using DFT calculations and compared to the percentage of unpaired anions as measured using Raman spectroscopy and the ionic conductivity. As shown in Figure 6, for electrolytes based on $\mathrm{Li}, \mathrm{Na}$, $\mathrm{K}, \mathrm{Al}, \mathrm{Mg}$, and $\mathrm{Ca}$, the variation in the ionic conductivity due to cation type is about two orders of magnitude at $100{ }^{\circ} \mathrm{C}$ and over three orders of magnitude at $-20^{\circ} \mathrm{C}$. Across these temperatures, lithiated electrolytes were the most conductive, while calcinated electrolytes were the least conductive. Surprising, aluminated electrolytes were found to have lower ionic conductivity than those with alkali $(+1)$ cations, but higher ionic conductivity than the alkaline earth $(+2)$ cations. Elemental analysis revealed that these electrolytes contain 1.5 times the aluminum predicted based upon $\mathrm{Al}(\mathrm{STFSI})_{3}$ complexation, thus, there are chloride anions remaining. The resultant aluminum chloride complexes (could include $\mathrm{AlCl}_{2}{ }^{+}, \mathrm{AlCl}_{4}{ }^{-}$, etc.) have faster transport rates in the polyether ionomer than the bare divalent cations $\mathrm{Mg}^{2+}$ and $\mathrm{Ca}^{2+}$. The low ionic conductivity of the hard divalent cations $\mathrm{Mg}^{2+}$ and $\mathrm{Ca}^{2+}$ in poly(ethylene oxide) has been documented in other works and is attributed to the divalent cation acting as a crosslinking point, strongly linking adjacent chains [51,52]. The conductivity of the $\mathrm{Na}$ and $\mathrm{K}$ containing electrolytes is close to that of the lithiated electrolyte at high temperatures, thus, we suggest that these electrolytes be further considered for use in elevated temperature $\mathrm{Na}$ and $\mathrm{K}$ battery systems.

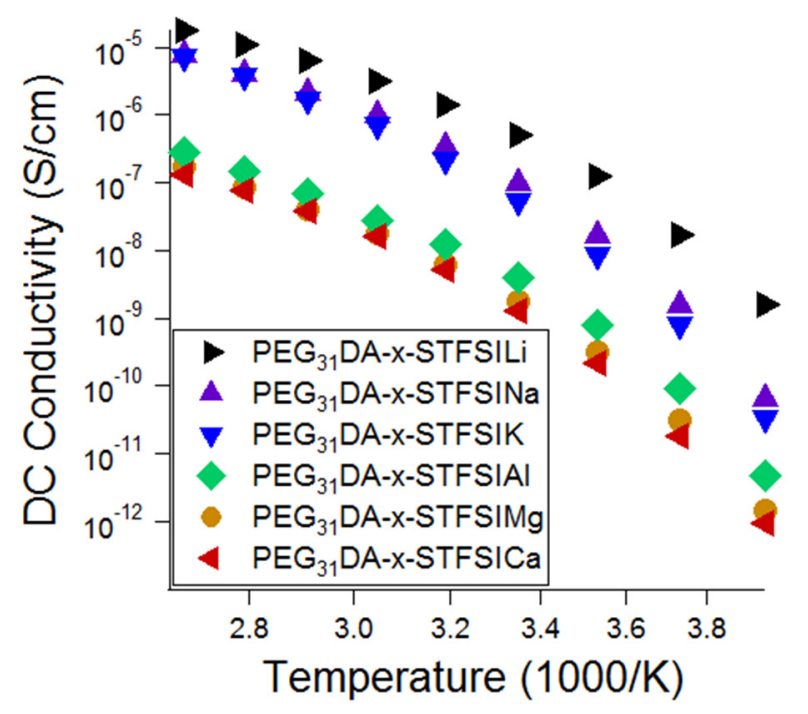

Figure 6. DC ionic conductivity from -20 to $100{ }^{\circ} \mathrm{C}$ for crosslinked electrolytes with varying cations.

Raman spectroscopy was used to further characterize the electrolytes to evaluate the relative influences of free cation number and cation mobility on ionic conductivity. First, theoretical Raman spectra were generated using DFT in order to support the experimental Raman peak identification. A directory summarizing the DFT inputs/outputs is available as Supplemental Materials. A DFT prediction using the PBE method with a $6311++G(d, p)$ basis for the LiSTFSI molecule showed that the vibrational mode that is associated with the S-N-S bonds expanding and contracting symmetrically was significantly affected by coordination with a cation. The shift from the free to the paired state was $\sim 18$ wavenumbers for coordination with $\mathrm{Li}^{+}$; specifically, the free peak was predicted at $691 \mathrm{~cm}^{-1}$ while the peak was predicted at $673 \mathrm{~cm}^{-1}$ for the lithiated anion. Furthermore, DFT predictions showed no significant Raman modes within $80 \mathrm{~cm}^{-1}$ of this characteristic STFSI peak, indicating that this peak would be relatively undisturbed by the surrounding signal from the STFSILi molecule. Shown in Figure 7 is the experimental Raman spectra for PEG $_{31}$ DA-x-STFSILi, and Figure 8 displays an enlarged view of the region of interest. The peak at $\sim 732 \mathrm{~cm}^{-1}$ is attributed to the unpaired STFSI- population, whereas the peak at $746 \mathrm{~cm}^{-1}$ is attributed to the STFSILi ion pair. Note that these modes occur at wavenumbers similar to that found for the common TFSI- anion, $\mathrm{CF}_{3} \mathrm{SO}_{2} \mathrm{NSO}_{2} \mathrm{CF}_{3}{ }^{-}$[26,53,54]. 
In no case could a peak be identified at a sufficient signal-to-noise ratio that corresponded to the cationic triplet, STFSILi ${ }_{2}{ }^{+}$. Notably, the Raman spectra of the electrolytes with varying metal cations appeared quite similar in this region in that two distinct peaks were apparent that we attribute to free STFSI and paired STFSI. For divalent metal cations, non-negligible populations of the neutral triplet are anticipated, i.e., $\mathrm{STFSI}_{2} \mathrm{Mg}$. The peak associated with this neutral triplet is predicted to occur close to that STFSIMg ${ }^{+}$, but could not be unambiguously identified at the level of noise present. Thus, in the following estimations of free and paired STFSI populations for the $\mathrm{Mg}$ and Ca-exchanged electrolytes, both the charged and neutral triplets are accounted for as part of the paired STFSI population. Unfortunately, the Al-exchanged electrolyte PEG $_{31} \mathrm{DA}-\mathrm{x}-\mathrm{STFSIAl}$ was opaque and, thus, the collected signal intensity was not high enough to produce a meaningful Raman spectrum for this composition.

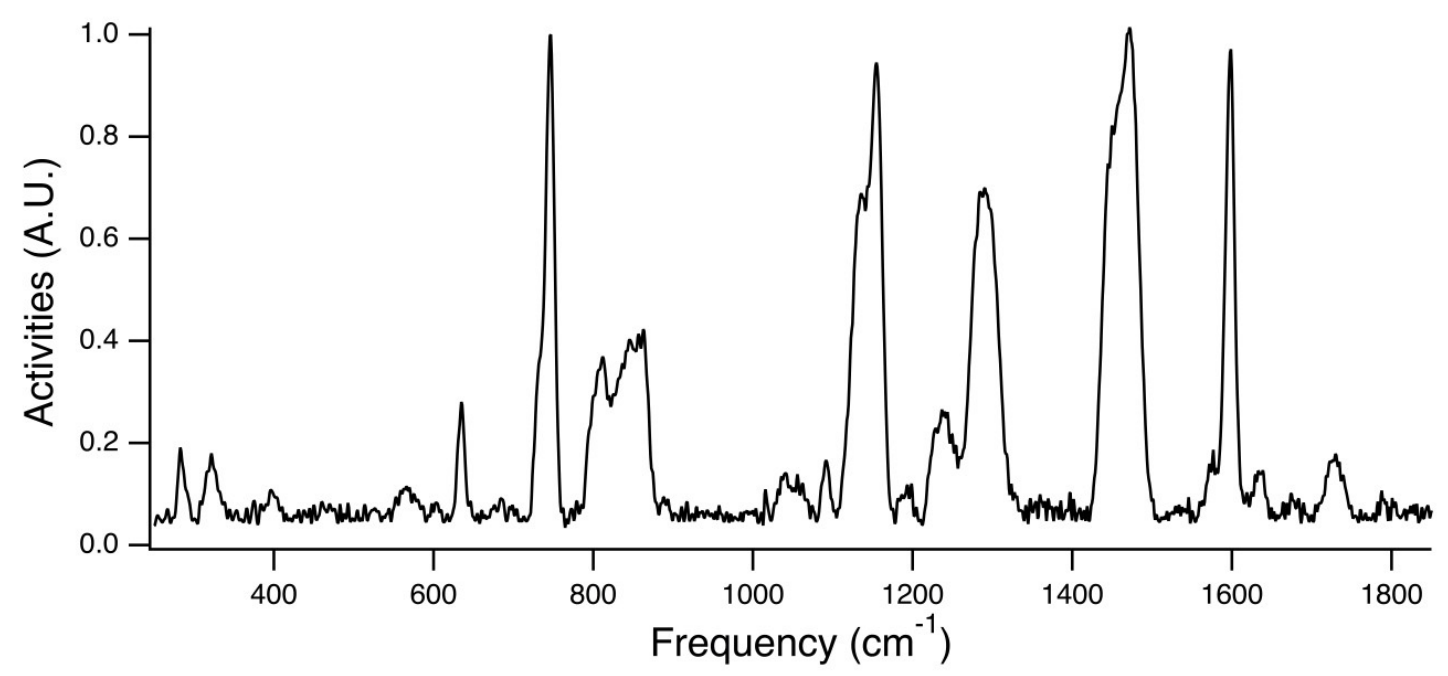

Figure 7. Experimental Raman spectrum of PEG $_{31}$ DA-x-STFSILi.

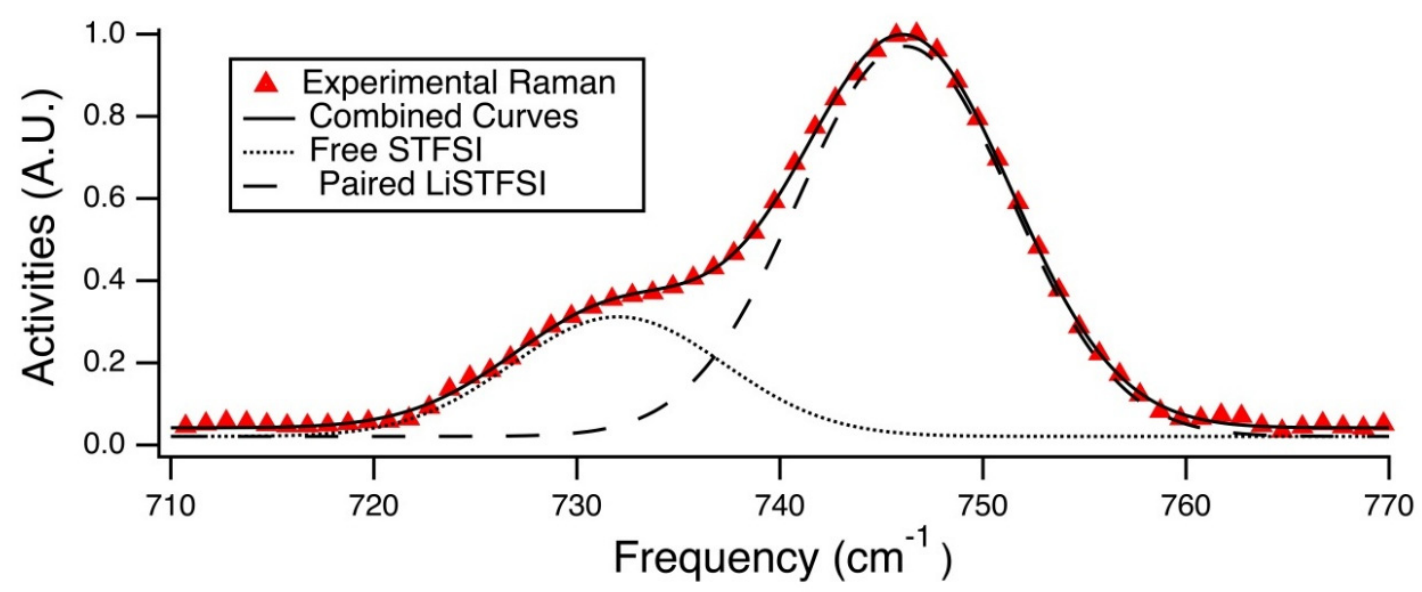

Figure 8. Peak fitting of PEG ${ }_{31}$ DA-x-STFSILi Raman spectrum to determine percentages of paired and unpaired (free) anions. The spectra for films of other compositions appeared quite similar.

Raman spectra were fit to provide estimations of the percentage of unpaired anions, see Figure 9a. For monovalent cations, the percentage of unpaired anions is exactly equivalent to the percentage of unpaired cations. Increasing ion size at equivalent valency, corresponding to decreased charge density, resulted in increased unpaired anion fractions. The highest unpaired fraction measured was $29 \pm 2 \%$ for K-exchanged electrolytes, compared with the lowest unpaired fraction of about $19 \%$ for Mg-exchanged electrolytes, a relative decrease of less than $35 \%$. This was found surprising given the 
three-fold difference in STFSI-cation binding energies as predicted from DFT, shown in Figure 9b. However, for divalent cations, this binding energy is that predicted for STFSI ${ }^{-}$and $\mathrm{X}^{2+}$; the binding energy for $\mathrm{STFSI}^{-}$and STFSIX ${ }^{+}$is expected to be considerably lower. Hence, for multivalent cations, the percentage of unpaired anions is not equivalent to the percentage of unpaired anions. Thus, with this analysis we are unable to unambiguously attribute the low divalent cation conductivity observed in Figure 6 to low numbers of mobile cations or low conducting cation mobility in the matrix.

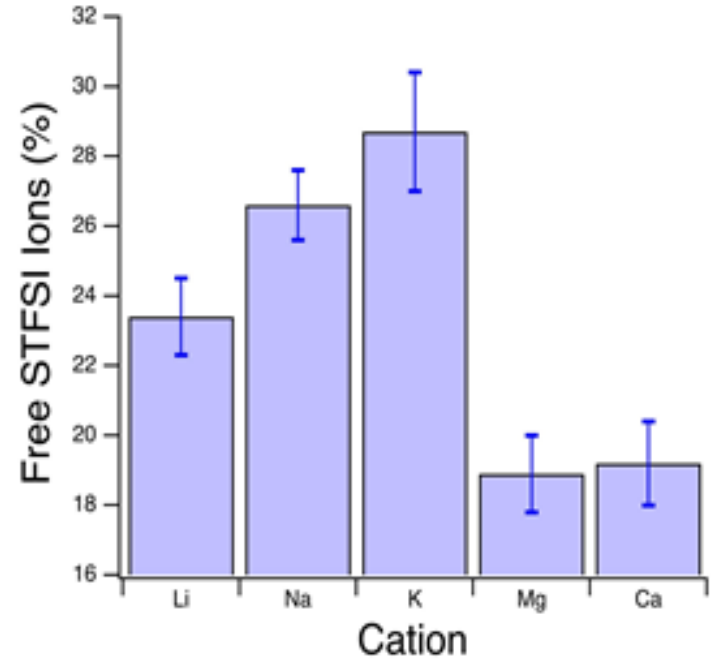

(a)

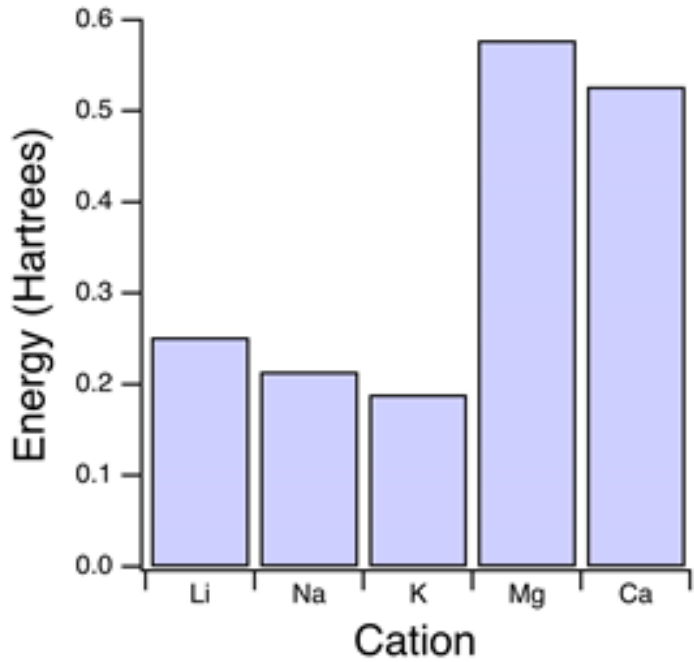

(b)

Figure 9. (a) Measured free ion percentages from Raman spectroscopy for PEG ${ }_{31} \mathrm{DA}-\mathrm{x}-\mathrm{STFSIX}$ electrolytes where $X$ is the variable cation, and (b) DFT predicted dissociation energies for STFSIX ion pairs where $X$ is the variable cation.

The number of free alkali cations, as determined from the total cation mass fraction and material density, may be used in concert with the conductivity equation and the Nernst-Einstein equation to provide an estimate of the conducting cation mobility for the case where the conducting species is the free, monatomic cation. The ionic conductivity, $\sigma$, is the product of the conducting ion number $(n)$, ion charge $(q)$, and ion mobility $(\mu)$ :

$$
\sigma=n q \mu
$$

The ion mobility is related to the ion diffusivity, $D$, as follows:

$$
D=\frac{\mu k T}{q}
$$

where $k$ is the Boltzmann constant and $T$ is the temperature. Using the unpaired cation fraction of $-23 \%$ for $\mathrm{Li}^{+}$as determined from Raman spectroscopy and a measured density of $1.28 \mathrm{~g} / \mathrm{mL}$, we estimate the $\mathrm{Li}^{+}$diffusivity in $\mathrm{PEG}_{31}$ DA-x-STFSILi as $6 \times 10^{-24} \mathrm{~cm}^{2} / \mathrm{s}$ at $20{ }^{\circ} \mathrm{C} \mathrm{Na}^{+}$and $\mathrm{K}^{+}$diffusivities at $20^{\circ} \mathrm{C}$ are estimated as $5 \times 10^{-25}$ and $3 \times 10^{-25} \mathrm{~cm}^{2} / \mathrm{s}$, respectively, for PEG $_{31}$ DA-x-STFSINa and PEG $_{31}$ DA-x-STFSIK.

The $\mathrm{Li}^{+}$diffusivity value estimated here should in the future be compared to the ${ }^{7} \mathrm{Li}$ self-diffusion coefficient as measured via pulse-field gradient nuclear magnetic resonance spectroscopy (PFG-NMR) [55]. While several other works have used Raman spectroscopy to estimate the degree of TFSI anion coordination in electrolytes such as ionic liquids, we believe that this is the first effort to apply this approach to single-ion conducting polymers with tethered STFSI anions. A prior work used FTIR to estimate the degree of tethered sulfonate coordination in a different single-ion conducting polymer [50]. Few simple methods exist for assessing the populations of free and coordinated cations, 
and diffusion coefficient measurements via PFG-NMR require more expensive instrumentation and are limited to certain nuclei such as ${ }^{7} \mathrm{Li}$ and ${ }^{1} \mathrm{H}$.

\section{Conclusions}

Several factors are found to influence the ionic conductivity of these PEGDA crosslinked single-ion conducting electrolytes, including crosslinker chain length and side-chains, anionic monomer proximity along the chain, tethered anion and counter-cation chemistry. We note that electrolytes prepared with PEGDA crosslinkers of at least $1600 \mathrm{~g} / \mathrm{mol}$ exhibit higher ionic conductivities over a wide temperature range. The addition of PEGMA side-chains was found to improve conductivity in limited cases. The tethered anion chemistry was found to strongly influence ionic conductivity, but more so at elevated temperatures. Lithiated electrolytes were found to exhibit the highest ionic conductivities, but the Na-exchanged and K-exchanged electrolytes exhibited conductivity as nearly as high at $100{ }^{\circ} \mathrm{C}$. The multivalent electrolytes were found to have significantly lower conductivities at all temperatures. It was demonstrated that percentages of unpaired STFSI anions may be quantified through the use of Raman spectroscopy measurements. This provides a measurement of the unpaired alkali cation population, but the multivalent cation states were not able to be quantified. We, therefore, suggest that future efforts in multivalent SIPEs be targeted toward characterization of cation states and solvation that ultimately dictate ionic conductivity.

\section{Materials and Methods}

\subsection{Materials}

The majority of chemicals were obtained from Sigma-Aldrich (St. Louis, MO, USA), including: poly(ethylene glycol) (PEG) of average molecular weights 1500, 2050, and $4600 \mathrm{~g} / \mathrm{mol}$, poly(ethylene glycol) methyl ether acrylate of average molecular weights 480 and $750 \mathrm{~g} / \mathrm{mol}$, poly(ethylene glycol) diacrylate of average molecular weight $700 \mathrm{~g} / \mathrm{mol}$, triethylamine, acryloyl chloride, thionyl chloride, oxalyl chloride, dichloromethane (DCM), tetrahydrofuran (THF), diethyl ether, anhydrous acetonitrile, dimethylformamide (DMF), methanol, pentane, 4-(dimethylamino)pyridine, lithium chloride, magnesium chloride, sodium chloride, aluminum chloride hexahydrate, calcium chloride, potassium carbonate, sodium bicarbonate, lithium hydride, hydrochloric acid, and 2-hydroxy-4'-(2-hydroxyethoxy)-2-methylpropiophenone (photoinitiator). Poly(ethylene glycol) diacrylate of average molecular weight $1000 \mathrm{~g} / \mathrm{mol}$ was obtained from Polysciences (Warrington, PA, USA). Trifluoromethanesulfonamide was obtained from TCI America (Portland, OR, USA). All reagents were used as received.

\subsection{Synthesis of Potassium 4-Styrenesulfonyl(trifluoromethylsulfonyl)imide (KSTFSI)}

KSTFSI was synthesized via a previously reported procedure [18]. Oxalyl chloride (20 g, $157 \mathrm{mmol}$ ) and $0.55 \mathrm{~mL}$ DMF were added to $250 \mathrm{~mL}$ anhydrous acetonitrile and stirred for five hours under a nitrogen atmosphere to form the yellow Vilsmeier-Haack complex. To this solution, $25 \mathrm{~g}$ (121 mmol) of 4-styrenesulfonate sodium salt were added and the mixture was stirred for one day. The resultant $\mathrm{NaCl}$ salt was removed from the 4-styrene sulfonyl chloride solution via filtration. Separately, $51 \mathrm{~mL}$ of triethylamine, $18.04 \mathrm{~g}$ trifluoromethylsulfonamide $(121 \mathrm{mmol})$, and $9 \%$ by weight 4-(dimethylamino)pyridine were added to $188 \mathrm{~mL}$ of anhydrous acetonitrile and allowed to dissolve under nitrogen. This solution was added dropwise to the 4 -styrene sulfonyl chloride solution at $0{ }^{\circ} \mathrm{C}$, and then stirred for $16 \mathrm{~h}$. The final solution was concentrated via rotary evaporation, and the resultant solids were dissolved in $50 \mathrm{~mL}$ of dichloromethane. The dichloromethane solution was washed with $3 \times 90 \mathrm{~mL}$ of $4 \% \mathrm{NaHCO}_{3}$ followed by $2 \times 125 \mathrm{~mL}$ of $1 \mathrm{M}$ hydrochloric acid. The washed organic solution was concentrated, with the acid monomer residue neutralized by the addition of one molar excess of $\mathrm{K}_{2} \mathrm{CO}_{3}$ dissolved in deionized (DI) water. The KSTFSI monomer was obtained by subsequent recrystallizations from DI water until confirmed pure via ${ }^{1} \mathrm{H}$ and ${ }^{13} \mathrm{C}$ NMR. 


\subsection{Synthesis of Lithium 1-[3-(Acryloyloxy)propylsulfonyl]-1-(trifluoromethane-sulfonyl)imide (LiAPTFSI)}

LiAPTFSI was synthesized via a previously reported procedure [56]. Briefly, the purchased potassium 3-(acryloyloxy)propane-1-sulfonate was dried and then converted to 3-(chlorosulfonyl)propyl acrylate via reaction with excess thionyl chloride. Then, 3-(chlorosulfonyl)propyl acrylate was converted to triethyl ammonium 1-[3-(acryloyloxy)propylsulfonyl]-1-(trifluoromethane-sulfonyl)imide by reaction with trifluoromethanesulfonamide in the presence of trimethylamine. The monomer was then lithiated by reaction with lithium hydride ( 2.5 times excess) in THF. The product was recrystallized from dichloromethane, washed with pentane, and dried under high vacuum. The structure was confirmed via ${ }^{1} \mathrm{H}$ and ${ }^{13} \mathrm{C}$ NMR though the yield was low (21\% for the final lithiation and purification steps).

\subsection{Synthesis of Poly(ethylene glycol) Diacrylate (PEGDA)}

PEGDA was synthesized in accordance with prior literature [57]. PEGs $\left(M_{n}=1500,2050\right.$, and $4600 \mathrm{~g} / \mathrm{mol}$ ) were dissolved in DCM and reacted with triethylamine and 2.2 equivalents of acryloyl chloride in a dark environment at $0{ }^{\circ} \mathrm{C}$ (gradually increasing to room temperature) under a nitrogen atmosphere. The solution was concentrated via rotary evaporation to roughly $25 \%$ of the original volume, to which THF was added to precipitate triethylamine hydrochloride salts. The solution was then further concentrated to an oily residue, dissolved in $5 \mathrm{~mL}$ dichloromethane, and precipitated in chilled diethyl ether. The PEGDA monomer was collected via filtration and dried under vacuum for $24 \mathrm{~h}$. Attachment of acrylate groups and purity was confirmed by ${ }^{1} \mathrm{H}$ NMR.

\subsection{Preparation of Crosslinked Electrolytes}

PEGDA of the required molecular weight was dissolved in DMF. The ionic monomer was added in the ratio of 30 PEGDA ethylene oxide units to one ionic monomer, and photoinitiator was added at the molar ratio of $0.01 \mathrm{~mol} / \mathrm{mol}$ monomer. The mixture was exposed to UV radiation (UVC 515 Ultraviolet Multilinker, Ultra-Lum, Inc., Carson, CA, USA) and heated to $80^{\circ} \mathrm{C}$ for the polymerization reaction. The polymerized films were then washed and ion-exchanged to the form of interest. First, the films were transferred to methanol, then to a $0.4 \mathrm{M}$ aqueous ion exchange solution for $96 \mathrm{~h}$ with solution changes every $24 \mathrm{~h}$ and, finally, a pure water bath. The films were dried in the open atmosphere for $24 \mathrm{~h}$, and finally dried in a glovebox under vacuum at $80^{\circ} \mathrm{C}$ for $16 \mathrm{~h}$.

\subsection{Ionic Conductivity}

Film conductivity was measured using a Broadband Dielectric/Impedance Spectrometer model Alpha A (Novocontrol Technologies, Montabaur, Germany) with symmetric brass electrodes. Measurements were taken at $15{ }^{\circ} \mathrm{C}$ intervals from $-20{ }^{\circ} \mathrm{C}$ to $100{ }^{\circ} \mathrm{C}$. AC voltage was set to $0.1 \mathrm{~V}$ and the frequency was swept from $10^{7} \mathrm{~Hz}$ to $0.1 \mathrm{~Hz}$.

\subsection{Thermal Properties}

The glass transition temperature $\left(T_{g}\right)$ and melting temperature $\left(T_{m}\right)$ were measured using differential scanning calorimetry (Mettler Toledo, DSC 1, Columbus, OH, USA) at a heating rate of $10^{\circ} \mathrm{C} \mathrm{min}-1$ under a nitrogen atmosphere, on the second heating leg of a heat-cool-heat cycle.

\subsection{DFT Calculations}

Geometric optimizations and single point energy calculations of anion-cation systems were used to calculate dissociation energies were performed in accordance with the widely-used three-parameter Becke model with the Lee-Yang-Par modification (B3LYP) [58,59]. The basis set that was used for all of the optimizations and single point energy calculations was $6-311++G(d, p)$, a large basis set containing diffusive functions that help deal with the distributed charge in the system, especially the anions in question. Dissociation energy correlations between different tethered anions in the system were determined starting with an optimization of the geometry of a single anion and a single monatomic 
cation. The final geometry for the molecule was then used to obtain a structure for the anion of the system. A single point energy calculation with the same method and basis was then performed on the anion. Additionally, a single point energy of the monatomic cation was also calculated. The three energies that had been calculated were then used to calculate a dissociation energy as shown in Figures 2 and 9. Dissociation energies were also tested with a varying size of bases, and were shown to converge to the reported values with increasing basis size. Furthermore, cations were placed in many different positions for the start of optimization in order to ensure the finding of the global minimum in calculations. It should also be noted that in the salt systems studied in this paper originally contained a double bond that was used to polymerize the salt to the PEGDA system. This double bond was altered to a fully-hydrogenated single bond in the DFT calculations in order to simulate a structure more similar to the ones present in the studied polymers. Various starting geometries were tested in order to ensure the global minimum of geometric optimization was found.

The method illustrated in Figure 10 was extended to many different anion-cation systems to obtain relative dissociation energy predictions. For the dissociation energy calculations of lithium 3-sulfopropyl acrylate (LiAPS) and lithium 4-propylacrylatesulfonyl(trifluoromethylsulfonyl)imide (LiAPTFSI), the oxygen atoms in the acrylate group were substituted with fully hydrogenated carbon atoms. The effect of the acryl oxygen atoms to the dissociation energy of LiSPA and LiSPTFSI in the real PEGDA-containing system is substantially diluted at the charge:EO ratio of 1:30, as used here.

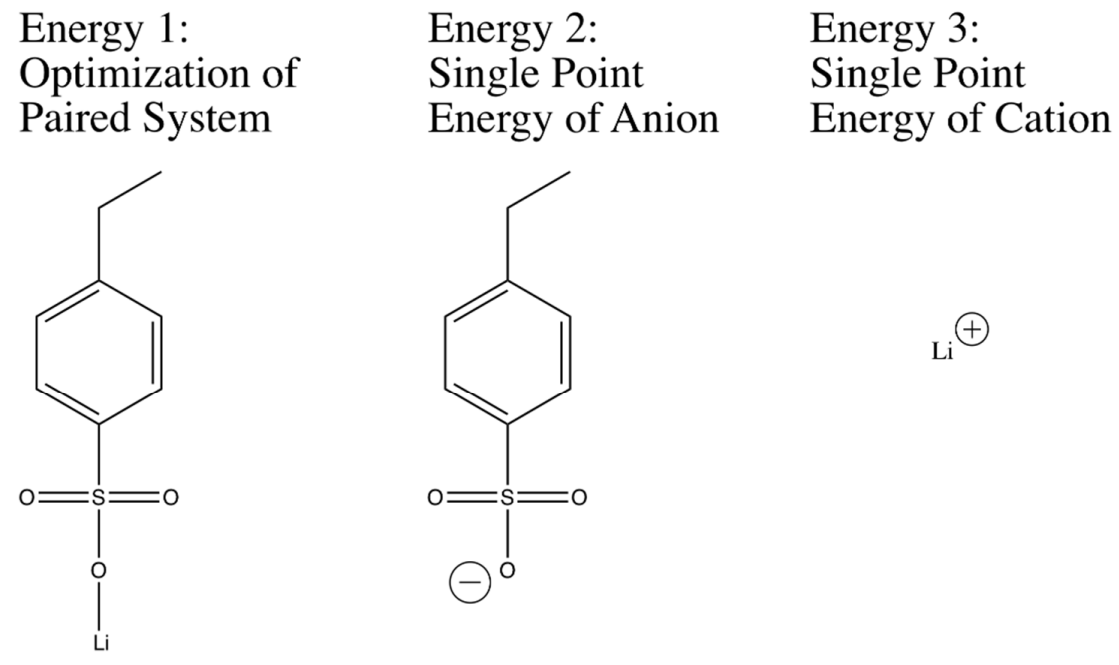

$$
\text { Dissocation Energy }=(\text { Energy } 2+\text { Energy } 3)-(\text { Energy } 1)
$$

Figure 10. Schematic to describe system states used in DFT calculations to determine a relative dissociation energy for a lithium styrene sulfonate (LiSS) ion pair.

Theoretical Raman spectroscopy was also calculated using the 6-311++G(d,p) basis set and the generalized gradient approximation (GGA) method proposed by Perdew, Burke, and Ernzhof [60]. This GGA method will be referred to as "PBE" throughout the rest of the paper. This method was used because it is known to give similar results to B3LYP with a much smaller computational cost. The specific peak shifts that were studied in this paper corresponded to the difference in anion's vibration when it was paired with a monatomic cation, as opposed to when it was in the unpaired, "free", state. These shifts were determined by optimizing the tethered anion and calculating a Raman spectrum then optimizing the free anion and calculating Raman spectrum for comparison. Shifts of interest, which contained the same vibrational modes, were determined by using the Avogadro software to visualize the calculated vibrations [61]. All calculations were performed using the Gaussian09 computational software [62]. 


\subsection{Raman Spectroscopy}

Polymer films that were previously prepared in an argon box were then placed in a Teflon-sealed quartz cuvette inside the same glove box. The samples were flush to the quartz glass when they were taken out of the glove box. Raman Measurements were taken using a NRS-5000 Mirco-Raman Spectrometer (Jasco, Inc., Easton, MD, USA) with the $20 \times$ objective magnification. A $532 \mathrm{~nm}$ excitation laser was used as well as a resolution of $13.8 \mathrm{~cm}^{-1}$. It should be noted that peak shapes were not significantly changed at a large range of resolutions $\left(0.7\right.$ to $\left.13.8 \mathrm{~cm}^{-1}\right)$, so the lowest resolution was used in order to increase the signal-to-noise ratio. The spectra were recorded every $1 \mathrm{~cm}^{-1}$.

Population analysis was done via Gaussian curve fitting of these Raman spectra in the range of $710 \mathrm{~cm}^{-1}$ to $770 \mathrm{~cm}^{-1}$. The peak at $746 \mathrm{~cm}^{-1}$ corresponds to the paired STFSI anion, and the shoulder occurring at a lower wavenumber corresponds to the free STFSI anion. Using this knowledge, the Beer-Lambert law was applied to the area integrations for the two Gaussian curves that were fit to the these modes, shown in Figure 8, in order to determine the fraction of free STFSI anions. It should be noted that this calculation of free ions did not take into account any cation-anion configurations other than a single anion bound to one monatomic cation. Other geometric possibilities that could be present and have similar Raman activities. These geometries for monovalent cations include the triplet (STFSILi ${ }_{2}+$ ), the negatively-charged coordination of two anions and one cation ([STFSI $\left.]_{2} \mathrm{Li}^{-}\right)$. For the divalent cations $\left([\mathrm{STFSI}]_{2} \mathrm{Mg}\right)$ is also a possibility. With relatively low signal-to-noise ratios, our analysis is somewhat restricted in determining which of these states are actually present in the electrolytes.

The error analysis that was performed on the free ion percentage calculations, shown in Figure 9, was done via Monte Carlo simulation. This was accomplished by taking a section of spectrum that was known to not have any signal and extracting an average random error to the known zero point. This random error was then introduced into the fitting Gaussian curves at random along the fitted curve. This new noisy curve was then fit using the same Gaussian curve fitting algorithm as the original data. The resulting two Gaussian curves were used to obtain a new population estimate. This population was stored, and the process was repeated 1000 times. A standard deviation was taken of all of the resulting population percentages, and a two standard deviation limit was placed on Figure 9 to depict a $95 \%$ confidence interval.

\subsection{Galvanostatic Cycling}

$\mathrm{Li} / \mathrm{PEG}_{31}$ DA-x-PEG ${ }_{14} \mathrm{MA}-\mathrm{x}-\mathrm{STFSILi} / \mathrm{Li}$ coin cells, size 2032, were assembled in an argon glovebox. After a $24 \mathrm{~h}$ rest at room temperature and one hour rest at $70{ }^{\circ} \mathrm{C}$, the coin cell was galavanostatically cycled at a rate of $50 \mu \mathrm{A} / \mathrm{cm}^{2}$ for $2 \mathrm{~h}$ for each complete cycle at $70{ }^{\circ} \mathrm{C}$ using a BTS3000 battery tester (Neware, Shenzhen, China) with wiring into a gravity oven (VWR, Radnor, PA, USA).

\subsection{Small Angle and Wide Angle X-Ray Scattering (SAXS-WAXS)}

SAXS-WAXS measurements were obtained using the Advanced Photon Source (beamline 12-ID-B, operated by the Chemical and Materials Science Group) at Argonne National Lab, with an X-ray beam wavelength of $0.9322 \AA$ (photon energy of $13.3 \mathrm{keV}$ ). The $q$-range was calibrated using a silver behenate standard, and the sample to detector distance was maintained at $2013 \mathrm{~mm}$ for the SAXS detector and $430.15 \mathrm{~mm}$ for the WAXS detector. Samples were prepared by loading the polymer films into glass or quartz capillary tubes (Charles Supper Company, Natick, MA, USA) and which were then sealed with wax under an argon atmosphere. Two-dimensional (2D) spectra were obtained with an exposure time of one second, collected with a Pilatus 2M camera (Dectris, Baden-Dättwil, Switzerland) for SAXS and Pilatus 300 for WAXS, and converted to 1D spectra via azimuthal integration. Spectra were corrected for transmission and background, and analyzed using the Igor Pro-Irena SAS package to display an arbitrary intensity vs scattering vector $q$, for:

$$
q=4 \pi / \lambda * \sin (\theta)
$$


where $\lambda$ is the $X$-ray wavelength and $\theta$ is half of the scattering angle, $2 \theta$.

\subsection{Elemental Analysis}

Inductively coupled plasma optically emitting spectroscopy (ICP-OES) was completed using a PerkinElmer Optima 8000 to quantify the amount of metal in the polymer films. Samples were digested by refluxing for $16 \mathrm{~h}$ in concentrated nitric acid (70\%), then diluted to 5\% nitric acid using 18 $\mathrm{M} \Omega$ water. Calibration standards were made from $1000 \mathrm{ppm}$ standards in $2 \%$ nitric acid (TraceCERT from Sigma Aldrich).

Supplementary Materials: The following are available online at http:/ /www.mdpi.com/2313-0105/4/2/28/s1, directory of DFT inputs/outputs.

Author Contributions: Conceptualization: J.L.S.; methodology: C.T.E., M.E.S., H.O.F., and S.P.U.; software: C.T.E. and W.F.S.; validation: M.E.S., H.O.F., and J.L.S.; formal analysis: C.T.E. and M.E.S.; investigation: C.T.E., M.E.S., H.O.F., and L.C.M.; resources: W.F.S. and J.L.S.; data curation: C.T.E., H.O.F.; writing-original draft preparation: C.T.E., M.E.S., H.O.F., L.C.M., and J.L.S.; writing—review and editing: W.F.S. and J.L.S.; visualization: C.T.E., M.E.S., H.O.F., and J.L.S.; supervision: S.P.U.,W.F.S., and J.L.S.; project administration: J.L.S.; and funding acquisition: J.L.S.

Funding: This research was funded by the National Science Foundation (USA) through grant number CBET-1706370.

Acknowledgments: M.S. gratefully acknowledges financial support from ND Energy. The authors gratefully acknowledge use of the University of Notre Dame Materials Characterization Facility, Magnetic Resonance Facility, Center for Environmental Science and Technology, and Center for Research Computing. This research used resources of the Advanced Photon Source, a U.S. Department of Energy (DOE) Office of Science User Facility operated for the DOE Office of Science by Argonne National Laboratory under contract no. DE-AC02-06CH11357.

Conflicts of Interest: The authors declare no conflict of interest. The funding sponsors had no role in the design of the study; in the collection, analyses, or interpretation of data; in the writing of the manuscript; or in the decision to publish the results.

\section{Appendix A}

Table A1. Monomer ratios, thermal transition data, and DC ionic conductivity for crosslinked electrolytes of select compositions.

\begin{tabular}{|c|c|c|c|c|}
\hline Composition & Ratio $^{1}$ & $T_{g}\left({ }^{\circ} \mathrm{C}\right)^{2}$ & $T_{m}\left({ }^{\circ} \mathrm{C}\right)^{4}$ & $\sigma,{ }^{5} 55^{\circ} \mathrm{C}(\mathrm{S} / \mathrm{cm})$ \\
\hline PEG $_{13}$ DA-x-SSLi & $2.3 / 0 / 1$ & -28.4 & n.d. & $3.3 \times 10^{-9}$ \\
\hline PEG $_{13}$ DA-x-PEG 9 MA-x-SSLi $(80: 20)$ & $1.8 / 0.7 / 1$ & -37.5 & n.d. & $5.5 \times 10^{-9}$ \\
\hline PEG $_{13}$ DA-x-PEG 9 MA-x-SSLi $(60: 40)$ & $1.4 / 1.3 / 1$ & -46.9 & n.d. & $9.5 \times 10^{-10}$ \\
\hline PEG $_{13}$ DA-x-STFSILi & $2.3 / 0 / 1$ & -17.8 & n.d. & $1.7 \times 10^{-7}$ \\
\hline PEG $_{13}$ DA-x-PEG9MA-x-STFSILi (80:20) & $1.8 / 0.7 / 1$ & -23.4 & n.d. & $1.5 \times 10^{-7}$ \\
\hline PEG $_{13}$ DA-x-PEG 9 MA-x-STFSILi $(60: 40)$ & $1.4 / 1.3 / 1$ & -36.3 & n.d. & $4.3 \times 10^{-7}$ \\
\hline PEG $_{20} \mathrm{DA}-\mathrm{x}-\mathrm{SSLi}$ & $1.5 / 0 / 1$ & -36.2 & n.d. & $2.6 \times 10^{-8}$ \\
\hline $\mathrm{PEG}_{20} \mathrm{DA}-\mathrm{x}-\mathrm{VSLi}$ & $1.5 / 0 / 1$ & -47.6 & n.d. & $5.5 \times 10^{-8}$ \\
\hline $\mathrm{PEG}_{20} \mathrm{DA}-\mathrm{x}-\mathrm{APSLi}$ & $1.5 / 0 / 1$ & -42.3 & n.d. & $1.7 \times 10^{-7}$ \\
\hline $\mathrm{PEG}_{20}$ DA-x-APTFSILi & $1.5 / 0 / 1$ & -41.3 & n.d. & $1.6 \times 10^{-6}$ \\
\hline $\mathrm{PEG}_{20} \mathrm{DA}-\mathrm{x}-\mathrm{STFSILi}$ & $1.5 / 0 / 1$ & -34.4 & n.d. & $1.6 \times 10^{-6}$ \\
\hline $\mathrm{PEG}_{31}$ DA-x-STFSILi & $1 / 0 / 1$ & -38.5 & n.d. & $3.2 \times 10^{-6}$ \\
\hline $\mathrm{PEG}_{31}$ DA-x-STFSINa & $1 / 0 / 1$ & -36.9 & n.d. & $1.0 \times 10^{-6}$ \\
\hline PEG $_{31}$ DA-x-STFSIK & $1 / 0 / 1$ & -43.5 & 30.8 & $6.8 \times 10^{-7}$ \\
\hline PEG $_{31}$ DA-x-STFSIMg & $1 / 0 / 1$ & -35.4 & n.d. & $1.8 \times 10^{-8}$ \\
\hline $\mathrm{PEG}_{31}$ DA-x-STFSICa & $1 / 0 / 1$ & -42.0 & n.d. & $1.6 \times 10^{-8}$ \\
\hline PEG $_{31}$ DA- $x-S T F S I A l$ & $1 / 0 / 1$ & -42.5 & n.d. & $2.8 \times 10^{-8}$ \\
\hline $\mathrm{PEG}_{43} \mathrm{DA}-\mathrm{x}-\mathrm{STFSILi}$ & $0.7 / 0 / 1$ & -45.6 & 28.4 & $1.2 \times 10^{-6}$ \\
\hline PEG $_{111}$ DA-x-STFSILi & $0.3 / 1 / 1$ & n.d. ${ }^{3}$ & 41.8 & $5.7 \times 10^{-6}$ \\
\hline
\end{tabular}

${ }^{1}$ PEGDA/PEGMA/Anion monomer number ratio; ${ }^{2}$ glass transition temperature, accurate to $\pm 1{ }^{\circ} \mathrm{C} ;{ }^{3}$ n.d. $=$ not detectable; ${ }^{4}$ melting temperature, accurate to $\pm 1{ }^{\circ} \mathrm{C} ;{ }^{5} \mathrm{DC}$ ionic conductivity at $55^{\circ} \mathrm{C}$. 


\section{References}

1. Blomgren, G.E. The Development and Future of Lithium Ion Batteries. J. Electrochem. Soc. 2017, 164, A5019-A5025. [CrossRef]

2. Ngai, K.S.; Ramesh, S.; Ramesh, K.; Juan, J.C. A review of polymer electrolytes: Fundamental, approaches and applications. Ionics (Kiel) 2016, 22, 1259-1279. [CrossRef]

3. Wang, Y.; Chen, R.; Chen, T.; Lv, H.; Zhu, G.; Ma, L.; Wang, C.; Jin, Z.; Liu, J. Emerging non-lithium ion batteries. Energy Storage Mater. 2016, 4, 103-129. [CrossRef]

4. Choi, J.W.; Aurbach, D. Promise and reality of post-lithium-ion batteries with high energy densities. Nat. Rev. Mater. 2016, 1, 16013. [CrossRef]

5. Kalhoff, J.; Eshetu, G.G.; Bresser, D.; Passerini, S. Safer Electrolytes for Lithium-Ion Batteries: State of the Art and Perspectives. ChemSusChem 2015, 8, 2154-2175. [CrossRef] [PubMed]

6. Leadbetter, J.; Swan, L.G. Selection of battery technology to support grid-integrated renewable electricity. J. Power Sources 2012, 216, 376-386. [CrossRef]

7. Manthiram, A.; Yu, X.; Wang, S. Lithium battery chemistries enabled by solid-state electrolytes. Nat. Rev. Mater. 2017, 2, 16103. [CrossRef]

8. Hassoun, J.; Scrosati, B. Review-Advances in Anode and Electrolyte Materials for the Progress of Lithium-Ion and beyond Lithium-Ion Batteries. J. Electrochem. Soc. 2015, 162, A2582-A2588. [CrossRef]

9. Xue, Z.; He, D.; Xie, X. Poly(ethylene oxide)-based electrolytes for lithium-ion batteries. J. Mater. Chem. A 2015, 3, 19218-19253. [CrossRef]

10. Shaplov, A.S.; Marcilla, R.; Mecerreyes, D. Recent Advances in Innovative Polymer Electrolytes based on Poly(ionic liquid)s. Electrochim. Acta 2015, 175, 18-34. [CrossRef]

11. Fergus, J.W. Ceramic and polymeric solid electrolytes for lithium-ion batteries. J. Power Sources 2010, 195, 4554-4569. [CrossRef]

12. Zhang, H.; Li, C.; Piszcz, M.; Coya, E.; Rojo, T.; Rodriguez-Martinez, L.M.; Armand, M.; Zhou, Z. Single lithium-ion conducting solid polymer electrolytes: Advances and perspectives. Chem. Soc. Rev. 2017, 46, 797-815. [CrossRef] [PubMed]

13. Ma, Q.; Zhang, H.; Zhou, C.; Zheng, L.; Cheng, P.; Nie, J.; Feng, W.; Hu, Y.S.; Li, H.; Huang, X.; et al. Single lithium-ion conducting polymer electrolytes based on a super-delocalized polyanion. Angew. Chem.-Int. Ed. 2016, 55, 2521-2525. [CrossRef] [PubMed]

14. Mazor, H.; Golodnitsky, D.; Peled, E.; Wieczorek, W.; Scrosati, B. A search for a single-ion-conducting polymer electrolyte: Combined effect of anion trap and inorganic filler. J. Power Sources 2008. [CrossRef]

15. Rojas, A.A.; Inceoglu, S.; Mackay, N.G.; Thelen, J.L.; Devaux, D.; Stone, G.M.; Balsara, N.P. Effect of Lithium-Ion Concentration on Morphology and Ion Transport in Single-Ion-Conducting Block Copolymer Electrolytes. Macromolecules 2015, 48, 6589-6595. [CrossRef]

16. Bouchet, R.; Maria, S.; Meziane, R.; Aboulaich, A.; Lienafa, L.; Bonnet, J.-P.; Phan, T.N.T.; Bertin, D.; Gigmes, D.; Devaux, D.; et al. Single-ion BAB triblock copolymers as highly efficient electrolytes for lithium-metal batteries. Nat. Mater. 2013, 12, 452-457. [CrossRef] [PubMed]

17. Feng, S.; Shi, D.; Liu, F.; Zheng, L.; Nie, J.; Feng, W.; Huang, X.; Armand, M.; Zhou, Z. Single lithium-ion conducting polymer electrolytes based on poly[(4-styrenesulfonyl)(trifluoromethanesulfonyl)imide] anions. Electrochim. Acta 2013, 93, 254-263. [CrossRef]

18. Meziane, R.; Bonnet, J.P.; Courty, M.; Djellab, K.; Armand, M. Single-ion polymer electrolytes based on a delocalized polyanion for lithium batteries. Electrochim. Acta 2011, 57, 14-19. [CrossRef]

19. Fragiadakis, D.; Dou, S.; Colby, R.H.; Runt, J. Molecular mobility and Li+ conduction in polyester copolymer ionomers based on poly(ethylene oxide). J. Chem. Phys. 2009, 130, 064907. [CrossRef] [PubMed]

20. Dou, S.; Zhang, S.; Klein, R.J.; Runt, J.; Colby, R.H. Synthesis and characterization of poly(ethylene glycol)-based single-ion conductors. Chem. Mater. 2006, 18, 4288-4295. [CrossRef]

21. Watanabe, M.; Suzuki, Y.; Nishimoto, A. Single ion conduction in polyether electrolytes alloyed with lithium salt of a perfluorinated polyimide. Electrochim. Acta 2000, 45, 1187-1192. [CrossRef]

22. Doyle, M.; Fuller, T.F.; Newman, J. The importance of the lithium ion transference number in lithium/polymer cells. Electrochim. Acta 1994, 39, 2073-2081. [CrossRef] 
23. Van Humbeck, J.F.; Aubrey, M.L.; Alsbaiee, A.; Ameloot, R.; Coates, G.W.; Dichtel, W.R.; Long, J.R. Tetraarylborate polymer networks as single-ion conducting solid electrolytes. Chem. Sci. 2015, 6, 5499-5505. [CrossRef] [PubMed]

24. Brandell, D.; Kasemägi, H.; Tamm, T.; Aabloo, A. Molecular dynamics modeling the Li-PolystyreneTFSI/PEO blend. Solid State Ion. 2014, 262, 769-773. [CrossRef]

25. Liang, S.; Choi, U.H.; Liu, W.; Runt, J.; Colby, R.H. Synthesis and Lithium Ion Conduction of Polysiloxane Single-Ion Conductors Containing Novel Weak-Binding Borates. Chem. Mater. 2012, 24, 2316-2323. [CrossRef]

26. Rey, I.; Johansson, P.; Lindgren, J.; Lassègues, J.C.; Grondin, J.; Servant, L. Spectroscopic and Theoretical Study of $\left(\mathrm{CF}_{3} \mathrm{SO}_{2}\right)_{2} \mathrm{~N}^{-}\left(\mathrm{TFSI}^{-}\right)$and $\left(\mathrm{CF}_{3} \mathrm{SO}_{2}\right)_{2} \mathrm{NH}$ (HTFSI). J. Phys. Chem. A 1998, 102, 3249-3258. [CrossRef]

27. Paranjape, N.; Mandadapu, P.C.; Wu, G.; Lin, H. Highly-branched cross-linked poly(ethylene oxide) with enhanced ionic conductivity. Polymer (Guildf) 2017, 111, 1-8. [CrossRef]

28. Daigle, J.-C.; Vijh, A.; Hovington, P.; Gagnon, C.; Hamel-Pâquet, J.; Verreault, S.; Turcotte, N.; Clément, D.; Guerfi, A.; Zaghib, K. Lithium battery with solid polymer electrolyte based on comb-like copolymers. J. Power Sources 2015, 279, 372-383. [CrossRef]

29. Liang, Y.-H.; Wang, C.-C.; Chen, C.-Y. Synthesis and characterization of a new network polymer electrolyte containing polyether in the main chains and side chains. Eur. Polym. J. 2008, 44, 2376-2384. [CrossRef]

30. Sun, X.G.; Kerr, J.B. Synthesis and characterization of network single ion conductors based on comb-branched polyepoxide ethers and lithium bis(allylmalonato)borate. Macromolecules 2006, 39, 362-372. [CrossRef]

31. Cowie, J.M.G.; Spence, G.H. Novel single ion, comb-branched polymer electrolytes. Solid State Ion. 1999, 123, 233-242. [CrossRef]

32. Aurbach, D.; Gofer, Y.; Lu, Z.; Schechter, A.; Chusid, O.; Gizbar, H.; Cohen, Y.; Ashkenazi, V.; Moshkovich, M.; Turgeman, R.; et al. A short review on the comparison between Li battery systems and rechargeable magnesium battery technology. J. Power Sources 2001, 97-98, 28-32. [CrossRef]

33. Meshram, P.; Pandey, B.D.; Mankhand, T.R. Extraction of lithium from primary and secondary sources by pre-treatment, leaching and separation: A comprehensive review. Hydrometallurgy 2014, 150, 192-208. [CrossRef]

34. Swain, B. Recovery and recycling of lithium: A review. Sep. Purif. Technol. 2017, 172, 388-403. [CrossRef]

35. Grosjean, C.; Miranda, P.H.; Perrin, M.; Poggi, P. Assessment of world lithium resources and consequences of their geographic distribution on the expected development of the electric vehicle industry. Renew. Sustain. Energy Rev. 2012, 16, 1735-1744. [CrossRef]

36. Yoo, H.D.; Shterenberg, I.; Gofer, Y.; Gershinsky, G.; Pour, N.; Aurbach, D. Mg rechargeable batteries: An on-going challenge. Energy Environ. Sci. 2013, 68, 1754-5692. [CrossRef]

37. Song, J.; Sahadeo, E.; Noked, M.; Lee, S.B. Mapping the Challenges of Magnesium Battery. J. Phys. Chem. Lett. 2016, 7, 1736-1749. [CrossRef] [PubMed]

38. Muldoon, J.; Bucur, C.B.; Gregory, T. Quest for nonaqueous multivalent secondary batteries: Magnesium and beyond. Chem. Rev. 2014, 114, 11683-11720. [CrossRef] [PubMed]

39. Dunn, B.; Kamath, H.; Tarascon, J.-M. Electrical energy storage for the grid: A battery of choices. Science 2011, 334, 928-35. [CrossRef] [PubMed]

40. Slater, M.D.; Kim, D.; Lee, E.; Johnson, C.S. Sodium-Ion Batteries. Adv. Funct. Mater. 2013, 23, 947-958. [CrossRef]

41. Ellis, B.L.; Nazar, L.F. Sodium and sodium-ion energy storage batteries. Curr. Opin. Solid State Mater. Sci. 2012, 16, 168-177. [CrossRef]

42. Pan, H.; Hu, Y.-S.; Chen, L. Room-temperature stationary sodium-ion batteries for large-scale electric energy storage. Energy Environ. Sci. 2013, 6, 2338. [CrossRef]

43. Wang, W.; Luo, Q.; Li, B.; Wei, X.; Li, L.; Yang, Z. Recent progress in redox flow battery research and development. Adv. Funct. Mater. 2013, 23, 970-986. [CrossRef]

44. Divya, K.C.; Østergaard, J. Battery energy storage technology for power systems-An overview. Electr. Power Syst. Res. 2009, 79, 511-520. [CrossRef]

45. Larcher, D.; Tarascon, J.-M. Towards greener and more sustainable batteries for electrical energy storage. Nat. Chem. 2015, 7, 19-29. [CrossRef] [PubMed]

46. Su, D.; McDonagh, A.; Qiao, S.-Z.; Wang, G. High-Capacity Aqueous Potassium-Ion Batteries for Large-Scale Energy Storage. Adv. Mater. 2017, 29, 1604007. [CrossRef] [PubMed] 
47. Chayambuka, K.; Mulder, G.; Danilov, D.L.; Notten, P.H.L. Sodium-Ion Battery Materials and Electrochemical Properties Reviewed. Adv. Energy Mater. 2018, 1800079. [CrossRef]

48. Elia, G.A.; Marquardt, K.; Hoeppner, K.; Fantini, S.; Lin, R.; Knipping, E.; Peters, W.; Drillet, J.-F.; Passerini, S.; Hahn, R. An Overview and Future Perspectives of Aluminum Batteries. Adv. Mater. 2016, 28, 7564-7579. [CrossRef] [PubMed]

49. Choi, U.H.; Mittal, A.; Price, T.L.; Lee, M.; Gibson, H.W.; Runt, J.; Colby, R.H. Molecular Volume Effects on the Dynamics of Polymerized Ionic Liquids and their Monomers. Electrochim. Acta 2015, 175, 55-61. [CrossRef]

50. Wang, J.H.H.; Yang, C.H.C.; Masser, H.; Shiau, H.S.; O'Reilly, M.V.; Winey, K.I.; Runt, J.; Painter, P.C.; Colby, R.H. Ion States and Transport in Styrenesulfonate Methacrylic PEO9 Random Copolymer Ionomers. Macromolecules 2015, 48, 7273-7285. [CrossRef]

51. Plancha, M.J.C. Characterisation and modeling of multivalent polymer electrolytes. In Polymer Electrolytes: Fundamentals and Applications; Sequeira, C., Santos, D., Eds.; Woodhead Publishing Limited: Philadelphia, PA, USA, 2010; pp. 340-377.

52. Ikeda, S.; Mori, Y.; Furuhashi, Y.; Masuda, H. Multivalent cation conductive solid polymer electrolytes using photo-cross-linked polymers: II. Magnesium and zinc trifluoromethanesulfonate systems. Solid State Ion. 1999, 121, 329-333. [CrossRef]

53. Seo, D.M.; Boyle, P.D.; Sommer, R.D.; Daubert, J.S.; Borodin, O.; Henderson, W.A. Solvate structures and spectroscopic characterization of litfsi electrolytes. J. Phys. Chem. B 2014, 118, 13601-13608. [CrossRef] [PubMed]

54. Fujii, K.; Fujimori, T.; Takamuku, T.; Kanzaki, R.; Umebayashi, Y.; Ishiguro, S.I. Conformational equilibrium of bis(trifluoromethanesulfonyl) imide anion of a room-temperature ionic liquid: Raman spectroscopic study and DFT calculations. J. Phys. Chem. B 2006, 110, 8179-8183. [CrossRef] [PubMed]

55. Lafemina, N.H.; Chen, Q.; Colby, R.H.; Mueller, K.T. The diffusion and conduction of lithium in poly(ethylene oxide)-based sulfonate ionomers. J. Chem. Phys. 2016, 145, 114903. [CrossRef]

56. Shaplov, A.S.; Vlasov, P.S.; Armand, M.; Lozinskaya, E.I.; Ponkratov, D.O.; Malyshkina, I.A.; Vidal, F.; Okatova, O.V.; Pavlov, G.M.; Wandrey, C.; et al. Design and synthesis of new anionic polymeric ionic liquids with high charge delocalization. Polym. Chem. 2011, 2, 2609-2618. [CrossRef]

57. Käpylä, E.; Delgado, S.M.; Kasko, A.M. Shape changing photodegradable hydrogels for dynamic 3D cell culture. ACS Appl. Mater. Interfaces 2016, 8, 17885-17893. [CrossRef] [PubMed]

58. Becke, A.D. Density-functional exchange-energy approximation with correct asymptotic behavior. Phys. Rev. A 1988, 38, 3098-3100. [CrossRef]

59. Lee, C.; Yang, W.; Parr, R.G. Development of the Colle-Salvetti correlation-energy formula into a functional of the electron density. Phys. Rev. B 1988, 37, 785-789. [CrossRef]

60. Perdew, J.P.; Burke, K.; Ernzerhof, M. Generalized Gradient Approximation Made Simple. Phys. Rev. Lett. 1996, 77, 3865-3868. [CrossRef] [PubMed]

61. Hanwell, M.D.; Curtis, D.E.; Lonie, D.C.; Vandermeersch, T.; Zurek, E. Hutchison, G.R. Avogadro: An advanced semantic chemical editor, visualization, and analysis platform. J. Cheminform. 2012, 4, 17. [CrossRef] [PubMed]

62. Gaussian 09 A.02; Gaussian, Inc.: Wallingford, CT, USA, 2009; pp. 2-3.

(C) 2018 by the authors. Licensee MDPI, Basel, Switzerland. This article is an open access article distributed under the terms and conditions of the Creative Commons Attribution (CC BY) license (http:/ / creativecommons.org/licenses/by/4.0/). 